\title{
PRODUÇÃO DE BIOMASSA DE CULTIVARES DE AVEIA SOB DIFERENTES MANEJOS DE CORTE ${ }^{1}$
}

\author{
José Valdir Demétrio ${ }^{2}$, Antonio Carlos Torres da Costa $^{3}$, Paulo Sérgio Rabello de Oliveira ${ }^{3}$
}

\section{ABSTRACT \\ BIOMASS YIELD OF OAT CULTIVARS UNDER \\ DIFFERENT CUTTING MANAGEMENT SYSTEMS}

In the crop-livestock integration system, improper oat management can result in low biomass yield. This study aimed to evaluate the effect of cutting management systems on the biomass yield of five oat cultivars with potential use in the crop-livestock integration system. A completely randomized blocks design with four replications, in a split-plot scheme, was used. The plots were represented by the oat cultivars Preta Comum, IAPAR 61, IPR 126, FAPA 2, and FUNDACEP FAPA 43. The Preta Comum cultivar features a short cycle, while the others have a long one. The sub-plots were represented by the following cutting systems: one single cut in the flowering stage, one cut in the vegetative and other in the flowering stage, two cuts in the vegetative and other in the flowering stage, and three cuts in the vegetative and other in the flowering stage. The long cycle cultivars (IAPAR 61, IPR 126, FAPA 2, and FUNDACEP FAPA 43) reached high forage yield, without affecting the subsequent fodder yield for soil covering, pointing out its ability to be used in crop-livestock systems. The management systems with three cuts in the vegetative stage maximizes the forage yield, however, concerning fodder yield, the best results were obtained by using up to two cuts in the vegetative stage, or a single one in the flowering stage.

KEY-WORDS: Avena spp.; soil cover; fodder; forage; croplivestock integration system.

\section{INTRODUÇÃO}

A cultura da aveia (Avena sp.) é uma das principais opções para cultivo na estação fria, especialmente no centro-sul do Brasil (Hartwing et al. 2006), sendo alternativa técnica e economicamente viável de cultivo, no período de outono/inverno/primavera. Além das aplicações como forrageira, destina-se à produção de grãos e, ainda, pode ser utilizada como cobertura verde/morta, para proteção e melhoria das

\section{RESUMO}

No sistema de integração lavoura-pecuária, o manejo inadequado da aveia pode resultar em baixo rendimento de biomassa. O objetivo deste trabalho foi avaliar o efeito do manejo de cortes na produção de biomassa, em cinco cultivares de aveia com potencial de uso no sistema de integração lavoura-pecuária. O delineamento adotado foi o de blocos completos casualizados, em esquema de parcelas subdivididas, com quatro repetições. As parcelas foram representadas pelas cultivares de aveia Preta Comum, IAPAR 61, IPR 126, FAPA 2 e FUNDACEP FAPA 43. A cultivar Preta Comum apresenta ciclo curto e as demais ciclo longo. As subparcelas foram representadas pelos seguintes sistemas de corte: corte único no florescimento, um corte na fase vegetativa e outro no florescimento, dois cortes na fase vegetativa e outro no florescimento e três cortes na fase vegetativa e outro no florescimento. As cultivares de ciclo longo (IAPAR 61, IPR 126, FAPA 2 e FUNDACEP FAPA 43) alcançaram alta produção de forragem, sem comprometer a posterior produção de palhada para a cobertura do solo, evidenciando aptidão para utilização no sistema de integração lavoura-pecuária. $\mathrm{O}$ manejo com três cortes no estádio vegetativo maximiza a produção de forragem, no entanto, para a produção de palhada, o melhor desempenho das cultivares foi obtido no manejo com até dois cortes na fase vegetativa, ou corte único no florescimento.

PALAVRAS-CHAVE: Avena spp.; cobertura do solo; palhada; forragem; sistema de integração lavoura-pecuária.

propriedades físicas, químicas e biológicas do solo, dando sustentabilidade ao sistema de semeadura direta (Floss et al. 2007) e à integração lavoura-pecuária (Carvalho et al. 2008).

O cultivo da aveia, em sistema de semeadura direta, é bastante difundido, devido ao alto rendimento de palhada, facilidade de aquisição de sementes e de implantação, rusticidade, rapidez de formação de cobertura, decomposição lenta e ciclo adequado (Silva et al. 2006). Como forrageira, por possuir

1. Trabalho recebido em nov./2011 e aceito para publicação em jun./2012 ( ${ }^{\circ}$ registro: PAT 16217).

2. Empresa de Assistência Técnica de Extensão Rural do Paraná (Emater), Santa Helena, PR, Brasil. E-mail: jvdemetrio@bol.com.br. 3. Universidade Estadual do Oeste do Paraná (Unioeste), Centro de Ciências Agrárias, Marechal Cândido Rondon, PR, Brasil. E-mails: antonio.costa2@unioeste.br, rabello.oliveira@hotmail.com. 
menos restrições, quanto à temperatura, no inverno, em relação ao azevém (amplamente utilizado no Rio Grande de Sul, Santa Catarina e centro-sul do Paraná), passou a ser considerada importante alternativa, sendo utilizada como forragem verde para pastejo, corte ou na sua forma conservada, como feno ou silagem (Moreira et al. 2005).

No Sul do País, o sistema de integração lavoura-pecuária preconiza a utilização de pastos de inverno para pastejo e, também, para formação de cobertura do solo, para a instalação do cultivo de verão (Carvalho et al. 2008). Todavia, em áreas de integração lavoura-pecuária, o manejo inadequado da aveia pode resultar em baixo rendimento de palhada, para proteção do solo no verão e para a semeadura direta das culturas seguintes, como a soja e o milho. Isto pode acarretar aumento na infestação de plantas daninhas e na dependência de controle químico na cultura sucessora, em relação aos sistemas que utilizam outras culturas para cobertura do solo, no inverno (Balbinot Júnior 2007).

Dentre as aveias, a mais cultivada é a aveia Preta Comum (Avena strigosa) (Ferolla et al. 2007), porém, a aveia Branca (Avena sativa) também apresenta grande potencial de utilização na alimentação animal e produção de palhada (Primavesi et al. 2004). O desenvolvimento de cultivares com ciclos vegetativos mais longos tem estimulado seu plantio (Bortoloni et al. 2005), tornando a aveia Branca importante componente em sistemas de produção agrícola, por possibilitar alta produção de forragem e palhada, em sistema de integração lavoura-pecuária com semeadura direta (Primavesi et al. 2004).

Por ocasião do corte da forragem, o sistema de desfolha provoca estresse na planta, pela remoção de área foliar, que, segundo o momento e intensidade da desfolha, afetará em maior ou menor grau o rendimento da forragem (Bortoloni et al. 2004). A resposta das plantas à desfolha é dependente da proporção de tecido removido, do grau de desfolhação da planta e das plantas vizinhas e da capacidade fotossintética das folhas remanescentes na planta (Confortin et al. 2010), uma vez que a intensidade da desfolha e o tempo para a recomposição foliar estão diretamente relacionados. Assim, as alturas de manejo de corte determinam a quantidade total de matéria seca (MS) produzida e a quantidade de MS reciclada no sistema (Aguinaga et al. 2008). O manejo destas alturas, à princípio, parece conflitante, uma vez que grande parte da biomassa produzida, que seria destinada à cobertura do solo, é destinada à alimentação de animais (Assmann \& Pin 2008). Dentre os componentes que alteram o desenvolvimento das plantas, o manejo de corte pode definir potencialmente o crescimento e a produtividade das pastagens (Skonieski et al. 2011).

Objetivou-se, com este trabalho, avaliar o efeito do manejo de cortes, na produção de biomassa de cinco cultivares de aveia com potencial de uso no sistema de integração lavoura-pecuária.

\section{MATERIAL E MÉTODOS}

O experimento foi conduzido em Latossolo Vermelho eutroférrico típico (Embrapa 2006), no

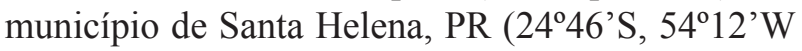
e $270 \mathrm{~m}$ de altitude), em 2008. O clima da região, segundo Köppen (Cfa), caracteriza-se como subtropical, com pluviosidade média anual de $1.800 \mathrm{~mm}$ (Iapar 2008). O resultado da análise química do solo, na camada $0-20 \mathrm{~cm}$, antes do cultivo da aveia, apresentou $\mathrm{pH}(\mathrm{CaCl} 2)=5,23 ; \mathrm{P}=22,98 \mathrm{mg} \mathrm{dm}^{-3}$; $\mathrm{Al}^{3+}=0,00 \mathrm{cmol}_{\mathrm{c}} \mathrm{dm}^{-3} ; \mathrm{Ca}^{2+}=6,85 \mathrm{cmol}_{\mathrm{c}} \mathrm{dm}^{-3} ; \mathrm{Mg}^{2+}=$ $1,65 \mathrm{cmol}_{\mathrm{c}} \mathrm{dm}^{-3} ; \mathrm{K}^{+}=0,58 \mathrm{cmol}_{\mathrm{c}} \mathrm{dm}^{-3} ; \mathrm{V}=75,76 \%$; e $\mathrm{MO}=3,55 \%$.

O delineamento experimental adotado foi o em blocos completos casualizados, em esquema de parcelas subdivididas, com quatro repetições. As parcelas foram representadas por cinco cultivares de aveia, sendo duas de aveia preta (Avena strigosa Schreb), de uso forrageiro (Preta Comum e IAPAR 61 Ibiporã), e três de aveia Branca (Avena sativa L.), de duplo propósito (IPR 126, FAPA 2 e FUNDACEP FAPA 43). A aveia Preta Comum apresenta ciclo curto, enquanto as demais apresentam ciclo longo.

As subparcelas foram representadas por quatro sistemas de manejo de corte: corte único no florescimento pleno, um corte na fase vegetativa e outro no florescimento pleno, dois cortes na fase vegetativa e outro no florescimento pleno e três cortes na fase vegetativa e outro no florescimento pleno. Os cortes para avaliar a produção de forragem, na fase vegetativa, em massa seca (MS), foram feitos entre $0,08 \mathrm{~m}$ e $0,10 \mathrm{~m}$ da superfície do solo, quando a altura média de plantas, medida em três pontos da subparcela, atingia de $0,35 \mathrm{~m}$ a $0,40 \mathrm{~m}$, e, no florescimento, foi realizado corte rente ao solo.

Cada parcela experimental teve área de $16,0 \mathrm{~m}$ de comprimento por 1,0 $\mathrm{m}$ de largura, constituída por cinco linhas da cultivar, com espaçamento entre as linhas de $0,2 \mathrm{~m}$. As subparcelas tinham as dimensões 
de 4,0 m de comprimento e 1,0 m de largura, sendo a primeira linha de cada lado e $0,5 \mathrm{~m}$ de cada extremidade considerados como bordadura.

A área onde foi conduzido o experimento era, anteriormente, ocupada com pasto (grama estrela africana - Cynodon nlemfuensis Vanderyst), sendo que, nos quatro últimos anos, esta passou a ser cultivada com culturas anuais, sendo o feijão a última cultura implantada na área.

O preparo do solo consistiu de uma escarificação, seguida de uma gradagem. Toda a área experimental foi adubada com $250 \mathrm{~kg} \mathrm{ha}^{-1}$ da fórmula 8-20-20 (Primavesi et al. 2004). A adubação e a semeadura foram efetuadas manualmente, com profundidade de semeadura de 2,0-3,0 cm, aplicando-se 80 sementes puras viáveis por metro linear. A adubação e a semeadura foram realizadas no dia 01/05/2008, sendo que a emergência das plântulas ocorreu num período de até dez dias após a semeadura.

$\mathrm{Na}$ fase inicial, foram efetuadas duas irrigações por aspersão (09 e 20/05/2008), com 15,0 mm de lâmina de água em cada uma. As precipitações pluviométricas, obtidas no local, e as temperaturas médias mensais da região, obtidas do Iapar (2008), no período experimental (maio a outubro), foram, respectivamente, de $96 \mathrm{~mm}, 125 \mathrm{~mm}, 95 \mathrm{~mm}$, $152 \mathrm{~mm}, 106 \mathrm{~mm}$ e $308 \mathrm{~mm}$ e $19^{\circ} \mathrm{C}, 16^{\circ} \mathrm{C}, 20^{\circ} \mathrm{C}$, $20^{\circ} \mathrm{C}, 19^{\circ} \mathrm{C}$ e $24^{\circ} \mathrm{C}$. Houve duas geadas intensas, nos dias 16 e 17/06/2008, mas que não comprometeram o rendimento.

A primeira parcela da adubação de cobertura foi realizada na fase de perfilhamento pleno ( 25 dias após a emergência), com $20 \mathrm{~kg} \mathrm{ha}^{-1}$ de nitrogênio, utilizando-se ureia como fonte. Por haver ocorrido, na ocasião do primeiro corte, acamamento excessivo de todas as cultivares, optou-se por suspender as aplicações de $\mathrm{N}$ em cobertura, nos parcelamentos seguintes. Para controle da ferrugem, foram realizadas três aplicações de Epoxiconazole + Pyraclostrobin, na dose de $1,0 \mathrm{~L} \mathrm{ha}^{-1}$ de produto comercial, realizadas em 16/07/2008, 06/08/2008 e 27/08/2008.

$\mathrm{Na}$ fase vegetativa, o primeiro corte foi realizado 30 dias após a emergência. O segundo corte, proveniente da rebrota, ocorreu 21 dias após o primeiro, e o terceiro corte, proveniente da segunda rebrota, foi realizado 24 dias após o segundo corte. Para a fase reprodutiva (florescimento), as datas de corte e o ciclo da cultura, em cada sistema de corte, estão apresentados na Tabela 1.

Os cortes foram efetuados manualmente, com o auxílio de faca, e foi efetuada a pesagem da massa verde da parte aérea. Para determinar a massa seca, retirou-se uma subamostra do material fresco colhido (aproximadamente $300 \mathrm{~g}$ ), a qual foi pesada, acondicionada em saco de papel, identificada e levada para estufa de circulação forçada de ar, a $65^{\circ} \mathrm{C}$, até peso constante.

Os dados foram submetidos a análise de variância (teste $\mathrm{F}$ ) e as médias foram comparadas pelo teste Tukey, a 5\%, utilizando-se o aplicativo estatístico SANEST (Zonta et al. 1985).

\section{RESULTADOS E DISCUSSÃO}

\section{Rendimento de forragem}

No manejo com um corte na fase vegetativa e outro no florescimento pleno, a cultivar FUNDACEP FAPA 43 produziu $1.302 \mathrm{~kg} \mathrm{ha}^{-1}$ de MS e não diferiu, estatisticamente, da cultivar FAPA 2, no entanto, diferiu das demais cultivares. Não houve diferença entre as cultivares IPR 126, Preta Comum e IAPAR 61, as quais apresentaram menor produção de massa seca do que a cultivar FAPA 43, mas não diferiram da FAPA 2, exceto a IPR 126 (Tabela 2).

Primavesi et al. (2006a) avaliaram cultivares de aveia, em São Carlos (SP), adubadas com

Tabela 1. Datas de corte no florescimento pleno e número de dias da emergência ao corte, de acordo com os sistemas de manejo de corte empregados (Santa Helena, PR, 2008).

\begin{tabular}{|c|c|c|c|c|c|c|c|c|}
\hline \multirow{3}{*}{ Cultivares } & \multicolumn{8}{|c|}{ Sistemas de manejo } \\
\hline & $\mathrm{F}^{*}$ & $\mathrm{VF}$ & $2 \mathrm{VF}$ & $3 \mathrm{VF}$ & $\mathrm{F}$ & VF & $2 \mathrm{VF}$ & $3 \mathrm{VF}$ \\
\hline & \multicolumn{4}{|c|}{ - Datas de corte } & \multicolumn{4}{|c|}{ Ciclo (dias após a emergência) } \\
\hline Preta comum & $08 / 08$ & $14 / 08$ & $22 / 08$ & $04 / 09$ & 90 & 96 & 104 & 117 \\
\hline IAPAR 61 & $17 / 09$ & $24 / 09$ & $02 / 10$ & $08 / 10$ & 130 & 137 & 145 & 151 \\
\hline IPR 126 & $17 / 08$ & $24 / 09$ & $02 / 10$ & $08 / 10$ & 130 & 137 & 145 & 151 \\
\hline FAPA 2 & $24 / 09$ & $02 / 10$ & $09 / 10$ & $15 / 10$ & 137 & 145 & 152 & 158 \\
\hline FUNDACEP FAPA 43 & $17 / 09$ & $24 / 09$ & $02 / 10$ & $08 / 10$ & 130 & 137 & 145 & 151 \\
\hline
\end{tabular}

* F: corte único no florescimento pleno; VF: um corte na fase vegetativa e um corte no florescimento pleno; $2 \mathrm{VF}$ : dois cortes na fase vegetativa e um corte no florescimento pleno; 3VF: três cortes na fase vegetativa e um corte no florescimento pleno. 
Tabela 2. Médias (de quatro repetições) de rendimento e rendimento total acumulado de massa seca de cultivares de aveia, no estádio vegetativo, de acordo com o sistema de manejo de corte (Santa Helena, PR, 2008).

\begin{tabular}{|c|c|c|c|c|c|}
\hline \multirow{3}{*}{ Cultivar } & \multicolumn{3}{|c|}{ Manejo de corte } & \multirow{2}{*}{$\begin{array}{c}\text { Total }^{2} \\
\text { acumulado }\end{array}$} & \multirow{2}{*}{$\begin{array}{l}\text { Média de } \\
\text { cultivar }\end{array}$} \\
\hline & $\mathrm{VF}^{1}$ & $2 \mathrm{VF}^{1}$ & $3 \mathrm{VF}^{1}$ & & \\
\hline & \multicolumn{5}{|c|}{ Matéria seca $\left(\mathrm{kg} \mathrm{ha}^{-1}\right)$} \\
\hline Preta Comum ${ }^{3}$ & $970 \mathrm{bcC}$ & $1.339 \mathrm{bB}$ & $1.596 \mathrm{bA}$ & $3.905 \mathrm{~b}$ & 1.302 \\
\hline IAPAR $61^{3}$ & $967 \mathrm{bcB}$ & $1.655 \mathrm{aA}$ & $1.775 \mathrm{abA}$ & $4.397 \mathrm{ab}$ & 1.466 \\
\hline IPR $126^{3}$ & $907 \mathrm{cB}$ & $1.644 \mathrm{aA}$ & $1.692 \mathrm{abA}$ & $4.243 \mathrm{ab}$ & 1.414 \\
\hline FAPA $2^{3}$ & $1.185 \mathrm{abC}$ & $1.440 \mathrm{abB}$ & $1.912 \mathrm{aA}$ & $4.537 \mathrm{a}$ & 1.512 \\
\hline FUNDACEP FAPA $43^{3}$ & $1.302 \mathrm{aB}$ & $1.247 \mathrm{bB}$ & $1.819 \mathrm{abA}$ & $4.368 \mathrm{ab}$ & 1.456 \\
\hline Média de corte ${ }^{4}$ & 1.066 & 1.465 & 1.759 & 4.290 & 1.430 \\
\hline
\end{tabular}

Médias seguidas da mesma letra minúscula, na coluna, e maiúscula, na linha, não diferem entre si, pelo teste Tukey, a $5 \%$. VF: um corte; 2 VF: dois cortes; 3 VF: três cortes. ${ }^{1} \mathrm{DMS}=273 \mathrm{~kg} \mathrm{ha}^{-1} ;{ }^{2} \mathrm{DMS}=565 \mathrm{~kg} \mathrm{ha}^{-1} ;{ }^{3} \mathrm{DMS}=232 \mathrm{~kg} \mathrm{ha}^{-1} ;{ }^{4} \mathrm{DMS}=104 \mathrm{~kg} \mathrm{ha}^{-1}$.

$250 \mathrm{~kg} \mathrm{ha}^{-1}$ da fórmula 10-30-10 e $20 \mathrm{~kg} \mathrm{ha}^{-1}$ de $\mathrm{N}$ em cobertura no perfilhamento, e obtiveram, para as cultivares Preta Comum, IAPAR 61, IPR 126, FAPA 2 e FUNDACEP FAPA 43, aos 41, 37, 41, 39 e 48 dias após a emergência (DAE), produção de forragem de $724 \mathrm{~kg} \mathrm{ha}^{-1}, 989 \mathrm{~kg} \mathrm{ha}^{-1}, 1.176 \mathrm{~kg} \mathrm{ha}^{-1}, 1.170 \mathrm{~kg} \mathrm{ha}^{-1}$ e $1.433 \mathrm{~kg} \mathrm{ha}^{-1}$ de massa seca, respectivamente. Fão et al. (2006) avaliaram cultivares de aveia, em Cruz Alta (RS), com aplicação de $200 \mathrm{~kg} \mathrm{ha}^{-1}$ da fórmula 5-20-20 no plantio e $20 \mathrm{Kg}$ de $\mathrm{N}$ no perfilhamento, e obtiveram, aos 74 DAE, para a cultivar Preta Comum, e aos 87 DAE, para as cultivares IAPAR 61, IPR 126, FAPA 2 e FUNDACEP FAPA 43 , respectivamente, $1.024 \mathrm{~kg} \mathrm{ha}^{-1}, 1.271 \mathrm{~kg} \mathrm{ha}^{-1}$, $1.265 \mathrm{~kg} \mathrm{ha}^{-1}, 1.671 \mathrm{~kg} \mathrm{ha}^{-1} \mathrm{e} 1.649 \mathrm{~kg} \mathrm{ha}^{-1}$ de massa seca, destacando-se a FUNDACEP FAPA 43, ou seja, em ambos os estudos, foram observadas produções de forragem semelhantes às obtidas nos manejos com até dois cortes, ao passo que, com três cortes, os valores encontrados no presente estudo são superiores aos relatados por Fão et al. (2006) e Primavesi et al. (2006a).

Bortolini et al. (2004) observaram que, quando a planta é submetida a cortes, há aumento de rendimento de MS, pois, segundo estes autores, os cortes conferem alta capacidade de rebrota e induzem à formação de novos perfilhos. Primavesi et al. (2007) recomendam a cultivar FUNDACEP FAPA 43, quando se deseja obter produção mais elevada no início do período de pastejo. Os resultados obtidos neste estudo corroboram a recomendação de Primavesi et al. (2007), pois esta cultivar produziu $1.302 \mathrm{~kg} \mathrm{ha}^{-1} \mathrm{de}$ MS, por ocasião do primeiro corte (Tabela 2).

Todas as cultivares sofreram acamamento, possivelmente pelas condições edafoclimáticas favoráveis, resultando em menor acúmulo de massa seca.
Segundo Bortolini et al. (2005), em anos favoráveis às culturas de inverno, tem sido constatado crescimento vegetativo exuberante, ocasionando altos índices de acamamento.

O rendimento médio de MS das cultivares, no manejo com dois cortes na fase vegetativa e outro no florescimento pleno, foi $27 \%$ supeior, em relação ao manejo com um corte na fase vegetativa (Tabela 2).

No manejo com dois cortes na fase vegetativa e outro no florescimento pleno, não houve diferença significativa $(p>0,05)$ entre as cultivares IAPAR 61 , IPR 126 e FAPA 2, as quais apresentaram maior produção de massa seca, com $1.655 \mathrm{~kg} \mathrm{ha}^{-1}, 1.644 \mathrm{~kg} \mathrm{ha}^{-1}$ e $1.440 \mathrm{~kg} \mathrm{ha}^{-1}$, respectivamente. Por outro lado, as cultivares FUNDACEP FAPA 43 e Preta Comum apresentaram menor produção de massa seca, com $1.247 \mathrm{~kg} \mathrm{ha}^{-1}$ e $1.399 \mathrm{~kg} \mathrm{ha}^{-1}$ (Tabela 2).

As diferenças de resposta de cada cultivar devem-se, principalmente, à capacidade de as plantas produzirem novos perfilhos, após o corte (Bortolini et al. 2004). Sá et al. (2006) observaram que as cultivares Preta Comum, IAPAR 61, IPR 126, FAPA 2 e FUNDACEPFAPA 43 produziram, respectivamente, $1.251 \mathrm{~kg} \mathrm{ha}^{-1}, 1.095 \mathrm{~kg} \mathrm{ha}^{-1}, 1.040 \mathrm{~kg} \mathrm{ha}^{-1}, 921 \mathrm{~kg} \mathrm{ha}^{-1}$ e $818 \mathrm{~kg} \mathrm{ha}^{-1}$ de massa seca, no segundo corte. Estes resultados são inferiores aos obtidos no presente trabalho. Tal fato provavelmente possa ser atribuído à combinação do conjunto de fatores relacionados à planta e às condições edafoclimáticas favoráveis, tais como distribuição relativamente uniforme das chuvas durante o período e alta fertilidade natural do solo, uma vez que a disponibilidade de nutrientes no solo tem grande importância no crescimento das forrageiras (Primavesi et al. 2004).

O rendimento médio de MS das cultivares, no manejo com três cortes na fase vegetativa e outro 
no florescimento pleno, foi $40 \%$ e $17 \%$ maior, em relação ao manejo com um e dois cortes na fase vegetativa, respectivamente (Tabela 2). Segundo Bortolini et al. (2004), este aumento de rendimento de MS, quando a planta é submetida a cortes, se expressa pela alta capacidade de rebrota e atividade de indução à formação de novos perfilhos.

No manejo com três cortes na fase vegetativa e outro no florescimento pleno, não houve diferença entre as cultivares FAPA 2, FUNDACEP FAPA 43, IPR 126 e IAPAR 61. Contudo, a cultivar FAPA 2 apresentou rendimento de $1.912 \mathrm{~kg} \mathrm{ha}^{-1}$ de massa seca, diferindo da cultivar Preta Comum. Estes resultados são superiores aos obtidos por Primavesi et al. (2007), que obtiveram, com as cultivares Preta Comum, IAPAR 61, IPR 126, FAPA 2 e FUNDACEP FAPA 43, respectivamente, $928 \mathrm{~kg} \mathrm{ha}^{-1}, 1.343 \mathrm{~kg} \mathrm{ha}^{-1}$, $1.024 \mathrm{~kg} \mathrm{ha}^{-1}, 1.493 \mathrm{~kg} \mathrm{ha}^{-1}$ e $1.457 \mathrm{~kg} \mathrm{ha}^{-1}$ de massa seca, aos 21, 40, 40, 48 e 27 dias após a rebrota do segundo corte, em São Carlos (SP), com o uso de $250 \mathrm{~kg}$ da fórmula 10-30-10 no plantio e $20 \mathrm{~kg} \mathrm{ha}^{-1}$ de $\mathrm{N}$ no perfilhamento e após cada corte.

Scheffer-Basso et al. (2001) avaliaram a cultivar Preta Comum, aos 31 dias após a rebrota do segundo corte, em Passo Fundo (RS), e, utilizando $300 \mathrm{~kg}$ da fórmula 5-25-25 no plantio e $30 \mathrm{~kg} \mathrm{ha}^{-1}$ de $\mathrm{N}$ no perfilhamento e após cada corte, obtiveram $628 \mathrm{~kg} \mathrm{ha}^{-1}$ de massa seca. Noro et al. (2003) obtiveram, com as cultivares Preta Comum e IAPAR 61, $586 \mathrm{~kg} \mathrm{ha}^{-1}$ e $677 \mathrm{~kg} \mathrm{ha}^{-1}$ de massa seca, respectivamente, aos 34 dias da rebrota do segundo corte, em Ibirubá (RS), utilizando $250 \mathrm{~kg} \mathrm{ha}^{-1}$ da fórmula 5-20-20 e $25 \mathrm{~kg}$ de N no perfilhamento e após cada corte. A cultivar Preta Comum, mesmo sendo a que tenha apresentado menor produção de forragem, no presente estudo, em relação às demais, promoveu maiores produções de forragem, em relação aos estudos citados acima, sobretudo nos manejos com dois e três cortes.

Ao analisar cada manejo de corte, pôde-se observar que cada cultivar também responde de forma diferente à desfolha ocasionada pelos manejos de corte. De maneira geral, observou-se aumento na produção de MS entre o manejo com um, dois e três cortes. Por ocasião do manejo com dois e três cortes, não foi observado acamamento das plantas provenientes da rebrota, no estádio vegetativo. Para Costa \& Markus (1977), isto é fator relevante, pois contribui, positivamente, para maior rendimento de MS. Bortoloni et al. (2004) observaram que a produ- ção de forragem, em plantas submetidas a um ou dois cortes, no estádio vegetativo, foi superior à obtida em plantas não cortadas. Estes autores concluíram que a produção de MS foi maior, quando realizados dois cortes no estádio vegetativo.

Em relação à produção acumulada de forragem nos três cortes, houve diferença significativa apenas entre as cultivares FAPA 2 e Preta Comum. A cultivar de aveia Preta Comum, material de maior precocidade, teve o menor rendimento acumulado. Por outro lado, o maior rendimento acumulado foi observado para a cultivar FAPA 2. Este comportamento está de acordo com o observado por Primavesi et al. (2006b), que afirmam que as cultivares de aveia de ciclo médio e ciclo longo foram até $46 \%$ mais produtivas que aquelas de ciclo precoce. Além disto, o menor rendimento de MS da aveia Preta Comum pode estar relacionado, também, ao hábito de crescimento desta cultivar, pois este contribui para o desenvolvimento de plantas daninhas (Fão et al. 2006), e a presença de plantas daninhas foi observada, principalmente, nas subparcelas onde encontrava-se a aveia Preta Comum.

O aumento gradual na produção de massa seca das cultivares, em decorrência do aumento no número de cortes (Tabela 2), é extremamente importante para a produção animal, especialmente para o rebanho leiteiro, pois coincide com a época de carência de forragem. A forma mais econômica de produção de leite, em geral, é aquela que consegue maximizar o componente forrageiro de pastagens bem manejadas (Fontaneli 2008).

\section{Rendimento de palhada}

No sistema com corte único no florescimento pleno, as cultivares FUNDACEP FAPA 43, IPR 126, IAPAR 61 e FAPA 2 foram as mais produtivas, diferindo da cultivar Preta Comum, a qual teve o menor rendimento de massa seca $\left(8.741 \mathrm{~kg} \mathrm{ha}^{-1}\right)$ (Tabela 3$)$. A cultivar Preta Comum apresentou menor produção em todos os cortes, em relação às demais.

Matzenbacher (2001), com corte único no florescimento, obteve, para a cultivar FAPA 2, produção de $12.970 \mathrm{~kg} \mathrm{ha}^{-1}$ de massa seca, e Sá et al. (2001) obtiveram, para as cultivares IAPAR 61 e IA96101-B (linhagem da atual IPR 126), no final de setembro, e para a cultivar Preta Comum, no final de agosto (todas no estádio de florescimento), em Londrina (PR), produção de $13.670 \mathrm{~kg} \mathrm{ha}^{-1}, 12.329 \mathrm{~kg} \mathrm{ha}^{-1} \mathrm{e}$ 
Tabela 3. Rendimento (média de quatro repetições) de palhada de cultivares de aveia, no florescimento pleno, de acordo com o manejo de corte, no período vegetativo (Santa Helena, PR, 2008).

\begin{tabular}{|c|c|c|c|c|c|}
\hline \multirow{3}{*}{ Cultivar } & \multicolumn{4}{|c|}{ Manejo de cortes } & \multirow{2}{*}{ Média } \\
\hline & $\mathrm{F}^{1}$ & $\mathrm{VF}^{1}$ & $2 \mathrm{VF}^{1}$ & $3 \mathrm{VF}^{1}$ & \\
\hline & \multicolumn{5}{|c|}{ - Rendimento de palhada $\left(\mathrm{kg} \mathrm{ha}^{-1}\right)$} \\
\hline Preta Comum ${ }^{2}$ & $8.741 \mathrm{bA}$ & $6.348 \mathrm{cB}$ & $5.185 \mathrm{cB}$ & $2.870 \mathrm{cC}$ & 5.786 \\
\hline IAPAR $61^{2}$ & $12.175 \mathrm{aA}$ & $12.112 \mathrm{bA}$ & $11.984 \mathrm{bA}$ & $7.740 \mathrm{bB}$ & 11.003 \\
\hline IPR $126^{2}$ & $12.362 \mathrm{aB}$ & $11.744 \mathrm{bB}$ & $13.909 \mathrm{aA}$ & $11.184 \mathrm{aB}$ & 12.300 \\
\hline FAPA $2^{2}$ & $12.172 \mathrm{aB}$ & $14.379 \mathrm{aA}$ & $14.407 \mathrm{aA}$ & $11.055 \mathrm{aB}$ & 13.003 \\
\hline FUNDACEP FAPA $43^{2}$ & $12.367 \mathrm{aA}$ & $10.592 \mathrm{bB}$ & $10.821 \mathrm{bB}$ & $8.315 \mathrm{bC}$ & 10.524 \\
\hline Média de cortes ${ }^{3}$ & 11.564 & 11.035 & 11.261 & 8.233 & 10.523 \\
\hline
\end{tabular}

$8.314 \mathrm{~kg} \mathrm{ha}^{-1}$ de massa seca, respectivamente, valores, estes, condizentes com as produções de palhada obtidas no presente estudo. Por outro lado, os resultados apresentados na Tabela 3 são superiores aos obtidos por Primavesi et al. (2006b), que obtiveram, no sistema com corte único no florescimento pleno, em São Carlos (SP), com as cultivares FAPA 2, IAPAR 61, IPR 126, FUNDACEP FAPA 43 e Preta Comum, produções de $9.813 \mathrm{~kg} \mathrm{ha}^{-1}, 9.601 \mathrm{~kg} \mathrm{ha}^{-1}$, $9.546 \mathrm{~kg} \mathrm{ha}^{-1}, 8.061 \mathrm{~kg} \mathrm{ha}^{-1}$ e $6.215 \mathrm{~kg} \mathrm{ha}^{-1}$ de massa seca, respectivamente, valores inferiores aos encontrados para as cultivares avaliadas neste estudo, inclusive para a Preta Comum.

No sistema com um corte na fase vegetativa e outro no florescimento pleno, a cultivar FAPA 2, com $14.379 \mathrm{~kg} \mathrm{ha}^{-1}$ de massa seca, foi a mais produtiva. Não houve diferença entre as cultivares IAPAR 61, IPR 126 e FUNDACEP FAPA 43. A cultivar Preta Comum manteve o menor rendimento de massa seca $\left(6.348 \mathrm{~kg} \mathrm{ha}^{-1}\right)$, em relação às demais.

No sistema com dois cortes na fase vegetativa e outro no florescimento pleno, as cultivares FAPA 2 e IPR 126 foram as que produziram mais palhada, com valor médio de $14.158 \mathrm{~kg} \mathrm{ha}^{-1}$ de massa seca. As cultivares IAPAR 61 e FUNDACEP FAPA 43 não diferiram entre si, e a cultivar Preta Comum produziu menos palhada que as demais. Este menor rendimento pode estar relacionado ao seu ciclo precoce. Conforme Fão et al. (2006), a cultivar Preta Comum apresenta hábito de crescimento ereto e, desta forma, reduz o sombreamento do solo, contribuindo para a infestação de plantas daninhas. Há correlação negativa entre quantidade de palha sobre o solo e infestação de plantas daninhas (Salvador et al. 2007).
No sistema com três cortes na fase vegetativa e outro no florescimento pleno, as cultivares IPR 126 e FAPA 2 apresentaram maior produção de palhada que as demais, com valor médio de $11.120 \mathrm{~kg} \mathrm{ha}^{-1}$ de massa seca. Por outro lado, as cultivares IAPAR $61 \mathrm{e}$ FUNDACEPFAPA 43 tiveram produção intermediária, com valor médio de $8.028 \mathrm{~kg} \mathrm{ha}^{-1}$ de massa seca. Já a cultivar Preta Comum obteve a menor produção de massa seca $\left(2.870 \mathrm{~kg} \mathrm{ha}^{-1}\right)$. Provavelmente, este decréscimo de produção da cultivar Preta Comum tenha ocorrido em razão do estádio fisiológico da planta, que, no terceiro corte, na fase vegetativa, já está finalizando seu ciclo (Primavesi et al. 2004). Segundo Gillet (1984), com os cortes frequentes, há acúmulo de material morto e lignificado na planta, prejudicando a qualidade e o desenvolvimento da forragem, por impedir a passagem de luz.

Com exceção da aveia Preta Comum, as demais cultivares podem ser utilizadas para a produção de forragem, em todos os sistemas de manejo, pois foram obtidos mais de $7.700 \mathrm{~kg} \mathrm{ha}^{-1}$ de massa seca, como cobertura do solo (Tabela 3 ). Cruz et al. (2001) afirmam que devem ser adotados sistemas de rotação de culturas que adicionem, pelo menos, $6.000 \mathrm{~kg} \mathrm{ha}^{-1}$ de massa seca por ano, à superfície do solo. Nestas condições, além de melhorar seus atributos químicos, físicos e biológicos, o solo mantido coberto evitará perdas de água por evaporação e, com isto, o sistema terá mais água armazenada no perfil do solo (Medeiros \& Calegari 2007).

\section{CONCLUSÕES}

1. As cultivares de aveia de ciclo longo (IAPAR 61, IPR 126, FAPA 2 e FUNDACEP FAPA 43) al- 
cançaram alta produção de forragem, sem comprometer a posterior produção de palhada, para a cobertura do solo, evidenciando alta aptidão para utilização no sistema de integração lavoura-pecuária.

2. O manejo com três cortes, no estádio vegetativo, maximiza a produção de forragem, no entanto, para produção de palhada, o melhor desempenho das cultivares foi observado no manejo com até dois cortes na fase vegetativa, ou corte único no florescimento.

\section{REFERÊNCIAS}

AGUINAGA, A. A. Q. et al. Componentes morfológicos e produção de forragem de pastagem de aveia e azevém manejada em diferentes alturas. Revista Brasileira de Zootecnia, Viçosa, v. 37, n. 9, p. 1523-1530, 2008.

ASSMANN, A. L.; PIN, E. A. Manejo de biomassa. In: SOARES, A. B.; ASSMANN, T. S.; ASSMANN, A. L. Integração lavoura-pecuária para a agricultura familiar. Londrina: Iapar, 2008. p. 11-14.

BALBINOT JÚNIOR, A. A. Uso do solo no inverno: propriedades do solo, incidência de plantas daninhas e desempenho da cultura do milho. 2007. 150 f. Tese (Doutorado em Produção Vegetal)-Universidade Federal do Paraná, Curitiba, 2007.

BORTOLINI, P. C. et al. Cereais de inverno submetidos ao corte no sistema de duplo propósito. Revista Brasileira de Zootecnia, Viçosa, v. 33, n. 1, p. 45-50, 2004.

BORTOLINI, P. C. et al. Produção de forragem e de grãos de aveia branca sob pastejo. Revista Brasileira de Zootecnia, Viçosa, v. 34, n. 6, p. 2192-2199, 2005.

CARVALHO, D. B. et al. Desenvolvimento de pastagens em integração lavoura-pecuária na região de Guarapuava PR. Revista Acadêmica: Agrárias e Ambientais, Curitiba, v. 6, n. 1, p. 11-19, 2008.

CONFORTIN, A. C. C. et al. Structural and morphogenical characteristics of black oats and Italian ryegrass on pasture submitted to two grazing intensities. Revista Brasileira de Zootecnia, Viçosa, v. 39, n. 11, p. 2357-2365, 2010.

COSTA, N. L.; MARKUS, R. Avaliação de cultivares de aveia (Avena spp.) para rendimento de forragem e grãos sob diferentes frequências de corte. Agronomia Sulriograndense, Porto Alegre, v. 13, n. 2, p. 337-346, 1977.

CRUZ, J. C. et al. Plantio direto e sustentabilidade agrícola. Informe Agropecuário, Belo Horizonte, v. 22, n. 208, p. 13-24, 2001.
EMPRESA BRASILEIRA DE PESQUISA AGROPECUÁRIA (Embrapa). Sistema brasileiro de classificação de solos. 2. ed. Rio de Janeiro: CNPS, 2006.

FÃO, V. de M. et al. Ensaio nacional de aveias forrageiras em Cruz Alta - RS, em 2005. In: REUNIÃO DA COMISSÃO BRASILEIRA DE PESQUISA DE AVEIA, 26., 2006, Guarapuava. Resultados experimentais... Guarapuava: Iapar, 2006. p. 141-143.

FEROLLA, F. S. et al. Produção de matéria seca, composição da massa de forragem e relação lâmina foliar/ caule + bainha de aveia-preta e triticale nos sistemas de corte e de pastejo. Revista Brasileira de Zootecnia, Viçosa, v. 36, n. 5, p. 1512-1517, 2007.

FLOSS, E. L. et al. Crescimento, produtividade, caracterização e composição química da aveia Branca. Acta Scientiarum Animal Science, Maringá, v. 29, n. 1, p. 1-7, 2007.

FONTANELI, R. S. Planejamento de pastagens: melhor caminho para produção de leite com qualidade e menor custo. Revista Plantio Direto, Passo Fundo, n. 104, 2008. Disponível em: <http://www.plantiodireto.com. br/?body=cont_int\&id=849>. Acesso em: 05 set. 2008.

GILLET, M. Las gramineas forrajeras. Zaragoza: Acribia, 1984.

HARTWIG, I. et al. Correlações fenotípicas entre caracteres agronômicos de interesse em cruzamentos dialélicos de aveia Branca. Revista Brasileira de Agrociência, Pelotas, v. 12, n. 3, p. 273-278, 2006.

INSTITUTO AGRONÔMICO DO PARANÁ (Iapar). Mapas climáticos. 2008. Disponível em: <http://www. iapar.br/modules/conteudo/conteudo.php?conteudo $=983>$. Acesso em: 05 set. 2008.

MATZENBACHER, R. G. Ensaio de aveias brancas de duplo-propósito na Fundacep, Cruz Alta, RS, em 2000. In: REUNIÃO DA COMISSÃO BRASILEIRA DE PESQUISA DE AVEIA, 21., 2001, Lages. Resultados experimentais... Lages: UDESC, 2001. p. 178-183.

MEDEIROS, G. B.; CALEGARI, A. Sistema plantio direto com qualidade: a importância do uso de plantas de cobertura num planejamento cultural estratégico. Revista Plantio Direto, Passo Fundo, n. 102, 2007. Disponível em: $<$ http://www.plantiodireto.com.br/?body=cont int\&id=836>. Acesso em: 05 set. 2008.

MOREIRA, A. L. et al. Avaliação da aveia Preta e de genótipos de aveia Amarela para produção de forragem. ARS Veterinária, Jaboticabal, v. 21, supl., p. 175-182, 2005.

NORO, G. et al. Gramíneas anuais de inverno para produção de forragem: avaliação preliminar de cultivares. Agrociência, Pelotas, v. 7, n. 1, p. 35-40, 2003. 
PRIMAVESI, A. C. et al. Resposta da aveia Branca à adubação em Latossolo Vermelho-Amarelo em dois sistemas de plantio. Revista Brasileira de Zootecnia, Viçosa, v. 33, n. 1, p. 79-86, 2004.

PRIMAVESI, O. et al. Avaliação de genótipos e recomendação de cultivares de aveia forrageira, na região Sudeste, para o ano de 2007. São Carlos: Embrapa Pecuária Sudeste, 2006a. (Comunicado técnico, 67).

PRIMAVESI, O. et al. Avaliação de genótipos e recomendação de cultivares de aveia para cobertura de solo, na região Sudeste, para o ano de 2007. São Carlos: Embrapa Pecuária Sudeste, 2006b. (Comunicado técnico, 66).

PRIMAVESI, O. et al. Avaliação de genótipos e recomendação de cultivares de aveia forrageira, na região central do Estado de São Paulo, no ano de 2008. São Carlos: Embrapa Pecuária Sudeste, 2007. (Comunicado técnico, 81).

SÁ, J. P. G. et al. Ensaio nacional de aveia forrageira, em Londrina, PR, 2005. In: REUNIÃO DA COMISSÃO BRASILEIRA DE PESQUISA DE AVEIA, 26., 2006, Guarapuava. Resultados experimentais... Guarapuava: Iapar, 2006. p. 144-145.

SÁ, J. P. G. et al. Ensaio regional de aveias de cobertura em Londrina, PR, 2000. In: RENIÃO DA COMISSÃO BRASILEIRA DE PESQUISA DE AVEIA, 21., 2001, Lages. Resultados experimentais... Lages: Iapar, 2001. p. 225-226.
SALVADOR, F. L. et al. Efeito da luz e da quebra de dormência na germinação de sementes de espécies de plantas daninhas. Revista Planta Daninha, Viçosa, v. 25, n. 2, p. 303-308, 2007.

SCHEFFER-BASSO, S. M. et al. Potencial de genótipos de aveia para duplo-propósito. Revista Brasileira de Agrociência, Pelotas, v. 7 n. 1, p. 22-28, 2001.

SILVA, P. R. F. da et al. Estratégias de manejo de coberturas de solo no inverno para cultivo do milho em sucessão no sistema semeadura direta. Ciência Rural, Santa Maria, v. 36, n. 3, p. 1011-1020, 2006.

SKONIESKI, F. R. et al. Composição botânica e estrutural e valor nutricional de pastagens de azevém consorciadas. Revista Brasileira de Zootecnia, Viçosa, v. 40, n. 3, p. 550556, 2011.

ZONTA, E. P. et al. Sistema de análise estatística (SANEST) para microcomputadores (versão 1). In: SIMPÓSIO DE ESTATÍSTICA APLICADA À EXPERIMENTAÇÃO AGRONÔMICA, 1., 1985, Piracicaba. Anais... Piracicaba: Fundação de Estudos Agrários Luiz de Queiroz, 1985. p. 74-90. 